\title{
RATCHETING SIMULATION IN A TITANIUM-STEEL BIMETALLIC PLATE BASED ON THE CHABOCHE HARDENING MODEL
}

\author{
Aleksander KAROLCZUK* \\ ${ }^{*}$ Faculty of Mechanical Engineering, Opole University of Technology, ul. Mikołajczyka 5, 45-271 Opole, Poland \\ a.karolczuk@po.opole.pl
}

received 4 May 2015, revised 22 November 2016, accepted 25 November 2016

\begin{abstract}
The paper presents the results of fatigue loading simulation applied to bimetallic model using the Chaboche kinematic hardening rule. Three cases of simulations were performed: (i) without residual stresses; (ii) considering residual stresses and (iii) considering asymmetrical geometry of bimetal, i.e. cross area reducing under tension period of loading. Experimental results exhibit the ratcheting phenomenon in titanium-steel bimetallic specimens. The observed ratcheting phenomenon could be explained by the third case of simulation which is supported by detection of microcracks in the vicinity of welded area.
\end{abstract}

Key words: Ratcheting Phenomenon, Explosive Welding, Cyclic Loading, The Chaboche Kinematic Hardening Model

\section{INTRODUCTION}

Bimetallic plates are sometimes required in specific industry equipment where different physical properties are needed in single plate. One layer of bimetallic plate offers for example excellent resistance against corroding medium and the second one provides appropriate mechanical stiffness and strength (Sulym et al., 2016; Ganczarski and Szubartowski, 2015). But, these different physical properties are often the reason that the required materials are unweldable by standard methods. In such case one of the alternatives is to use explosive welding technology (Findik, 2011; Crossland, 1982). This technology applies energy of detonation that accelerates one metallic material (the flayer) that collides to the base material and the metallic bond is formed. However, depending on explosive welding parameters and mechanical properties of parent materials the interface between the joint metals is characterized by different types of inhomogeneities (Paul et al., 2012; Lazurenko et al., 2016; Gloc et al., 2016). These inhomogeneities could be considered as defects and stress rising factors having influence on the monotonic and fatigue strengths (Song et al., 2011; Karolczuk et al., 2013). Besides, the unique mechanical and structural properties of joint area there are also residual stresses locked during explosive welding or introduced by the heat treatment (Karolczuk et al., 2014). Experimental tests under fully reversed cyclic loading exhibit ratcheting phenomenon in titanium-steel bimetallic specimens (Karolczuk et al., 2013). According to (Hubel, 1996) if the element has inhomogeneous elastic-plastic properties the structural ratcheting could appear since the two materials undergo plastic strains under different stress states.

There are two aims of the paper. The one is to show that the structural ratcheting in titanium-steel plate could not be simulated using the Chaboche hardening model even taking into account residual stresses. The second aim is to propose a model able to simulate the ratcheting phenomenon in the bimetallic plate.

\section{EXPERIMENT}

The tested and analyzed specimens were cut out from large bimetallic plate $(4330 \times 3150 \mathrm{~mm})$ obtained during explosive welding process. The titanium plate (Titanium Grade 1) with thickness equal to $6 \mathrm{~mm}$ was cladded on the steel plate $(\mathrm{S} 355 \mathrm{~J} 2+\mathrm{N})$ with thickness equal to $40 \mathrm{~mm}$. The part of plate for specimens was cut out from the corner and the ignition point was in the center of the plate. The chemical composition and basic mechanical properties of parent materials are presented in Tab. 1 and 2. The bimetallic plate after the welding process was subjected to the heat treatment. The heat treatment consists in soaking by 90 minutes at $600 \mathrm{oC}$. After the heat treatment the plate undergoes the cold flattening process. The flat specimens were cut out from the bimetallic plate and subjected to fatigue tests described in details in Karolczuk et al. (2013), Karolczuk and Kowalski, (2014).

Tab. 1. Chemical composition of parent materials

\begin{tabular}{|c|c|c|c|c|c|c|c|c|c|c|c|}
\hline \multicolumn{4}{|c|}{ S355J2+N steel (in weight-\%) } & \multicolumn{4}{|c|}{ Titanium Grade 1 (in weight-\%) } \\
\hline C & C & Si & Mn & P & S & C & Fe & H & N & O & Ti \\
\hline 0.22 & 0.22 & 0.55 & 1.60 & 0.025 & 0.025 & 0.10 & 0.20 & 0.015 & 0.03 & 0.18 & 99.5 \\
\hline
\end{tabular}

Tab. 2. Mechanical properties of $\mathrm{S} 355 \mathrm{~J} 2+\mathrm{N}$ steel and Tytanium Grade 1

\begin{tabular}{|c|c|c|c|c|c|}
\hline Material & $\mathbf{R}_{\text {eH, }} \mathbf{M P a}$ & $\mathbf{R}_{\mathbf{m}}, \mathbf{M P a}$ & $\mathbf{E}, \mathbf{G P a}$ & $\mathbf{v},-$ & $\mathbf{A}_{5}, \boldsymbol{\%}$ \\
\hline S355J2+N & $382-395$ & $598-605$ & $206-220$ & $0.27-0.30$ & $24-34$ \\
\hline Titanium Grade 1 & $189-215\left(\mathrm{R}_{\mathrm{p} 02}\right)$ & $308-324$ & $100-105$ & $0.37-0.39$ & $43-56$ \\
\hline
\end{tabular}

\section{THE CHABOCHE HARDENING MODEL}

The Chaboche model applied in simulation is a basic version consisted in the following decomposition rule of the kinematic hardening (Chaboche et al. 1979, 2012): 
$d \boldsymbol{a}=\sum_{i=1}^{3} d \boldsymbol{a}^{(i)}$,

$\mathrm{d} \boldsymbol{a}^{(i)}=\frac{2}{3} C^{(i)} d \varepsilon^{p}-\gamma^{(i)} \boldsymbol{a}^{(i)} d p$,

$d p=\sqrt{\frac{2}{3} d \varepsilon^{p}: d \varepsilon^{p}}$,

where: $a$ - back stress tensor, $C^{(i)}, \gamma^{(i)}$ - material parameters, $\varepsilon^{p}$ - plastic strain tensor, : - inner product, $d$ - increment. The constitutive equations (1) were completed with the associated flow rule:

$d \varepsilon^{p}=d \lambda \frac{\partial f}{\partial \boldsymbol{s}}=\frac{d s: \boldsymbol{n}}{H} \boldsymbol{n}$,

where: $H$ - the plastic modulus, $s$ - the deviatoric stress tensor, $n$ - tensor normal to yield surface $f$ of the Huber-Mises-Hencky hypothesis

$\frac{3}{2}(\boldsymbol{s}-\boldsymbol{a}):(\boldsymbol{s}-\boldsymbol{a})-\sigma_{y}^{2}=0$,

where $\sigma_{\mathrm{y}}$ is the yield stress.

\section{IDENTIFICATION OF MATERIALS PARAMETERS FOR THE CHABOCHE HARDENING MODEL}

One of the main problem in the Chaboche hardening model is identification of values of material parameters: $C^{(i)}, \gamma^{(i)}$. In the identification procedure the standard Ramberg-Osgood plastic strain-stress characteristic was used:

$\varepsilon_{a}^{p}=\left(\frac{\sigma_{\mathrm{a}}}{K^{\prime}}\right)^{1 / n^{\prime}}$,

where: $\varepsilon_{a}^{p}$ - plastic strain amplitude; $\sigma_{a}$ - stress amplitude; $K^{\prime}, n^{\prime}$ - cyclic hardening coefficient and exponent, respectively. The materials constants are presented in Tab. 3.

Tab. 3. Mechanical properties of S355J2+N steel and Titanium Grade 1 (Karolczuk and Kowalski, 2014; Gómez et al., 2011)

\begin{tabular}{|l|c|c|}
\hline Material & $\boldsymbol{K}^{\prime}, \mathbf{M P a}$ & $\boldsymbol{n}^{\prime}, \mathbf{-}$ \\
\hline S355J2+N & 721 & 0.1258 \\
\hline Titanium Grade 1 & 190 & 0.0641 \\
\hline
\end{tabular}

Under uniaxial stress state (monotonic tension) the constitutive equation of the Chaboche model could be solved and the relation between tension stress and plastic strain is as follows:

$\sigma_{\mathrm{a}}=\sigma_{\mathrm{y}}+\sum_{i=1}^{3} \frac{C^{(i)}}{\gamma^{(i)}}\left(1-e^{-\gamma^{(i)} \varepsilon_{\mathrm{a}}^{\mathrm{p}}}\right)$.

Identification procedure consisted in a minimization of parameter $\delta \mathrm{W}$ being the function of:

$\delta W=\frac{\int|\mathrm{d} W|}{W_{\mathrm{RO}}} 100 \%$

where: $W_{\mathrm{RO}}=\int\left(\varepsilon_{\mathrm{a}}^{\mathrm{p}}\right)^{n^{\prime}} K^{\prime} \mathrm{d} \varepsilon_{\mathrm{a}}^{\mathrm{p}}$,

$\mathrm{d} W=\left(\sigma_{\mathrm{y}}+\sum_{i=1}^{3} \frac{C^{(i)}}{\gamma^{(i)}}\left(1-e^{-\gamma^{(i)}} \varepsilon_{\mathrm{a}}^{\mathrm{p}}\right)-\left(\varepsilon_{\mathrm{a}}^{\mathrm{p}}\right)^{n \prime} K^{\prime}\right) d \varepsilon_{\mathrm{a}}^{\mathrm{p}}$.
In other words, it is a minimization of difference in plastic strain energy densities (areas under the curves $\varepsilon_{a}^{p}-\sigma_{a}$ ) calculated using both curves, i.e. eq. 4 and 5 . Minimization was performed using iteration algorithm of the interior point method (function fmincon in Matlab R2011b - optimization toolbox). Final fitting features between both curves are presented in Figs. 1 and 2. The values of determined material constants are presented in Tab. 4.
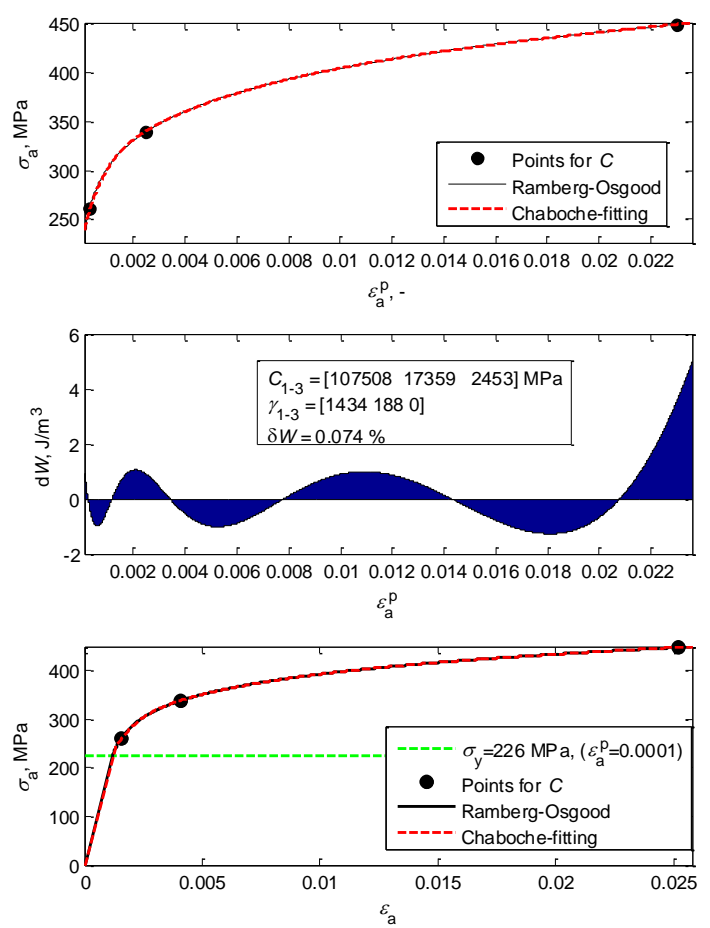

Fig. 1. The stress-strain curves and $d W$ (eq.8) parameter plots with the computed materials constants for the Chaboche model for the S355J2+N steel
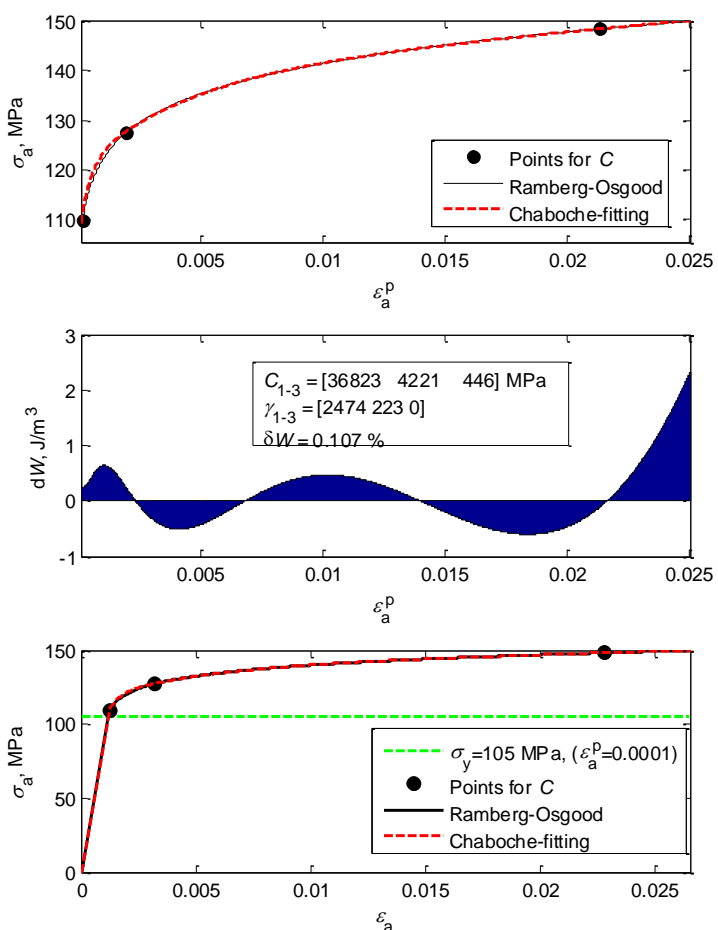

Fig. 2. The stress-strain curves and $d W$ (eq.8) parameter plots with the computed materials constants for the Chaboche model for the titanium grade 1 
Tab. 4. Material parameters for the Chaboche hardening model

\begin{tabular}{|c|c|c|c|c|c|c|c|c|}
\hline Material & $\sigma_{\mathrm{y}}, \mathrm{MPa}$ & $C^{(1)}, \mathrm{MPa}$ & $C^{(2)}, \mathrm{MPa}$ & $C^{(3)}, \mathrm{MPa}$ & $\gamma^{(1)}$ & $\gamma^{(2)}$ & $\gamma^{(3)}$ \\
\hline S355J2+N & 226 & 107508 & 17359 & 2453 & 1434 & 188 & 0 \\
\hline Titanium Grade 1 & 105 & 36823 & 4221 & 446 & 2474 & 223 & 0 \\
\hline
\end{tabular}

\section{BIMETALLIC MODEL}

Loading scheme and model geometry are presented in Fig. 3 The equilibrium equations were formulated with the following assumptions:

- full and perfect connection between metals in form of plane without defects,

- uniform distribution of strain increments $d \varepsilon$,

- stress increment distributions $d \sigma(T i), d \sigma(S t)$ are uniform for each layer,

- uniaxial stress state $\left(\sigma_{z z} \neq 0\right.$, Fig.3).

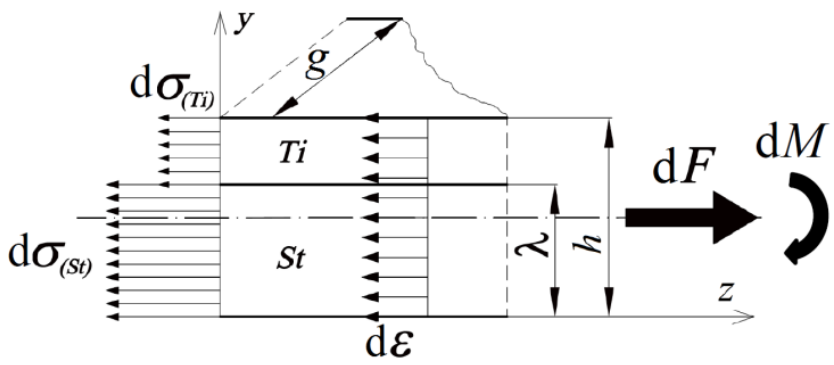

Fig. 3. Geometry and loading condition of bimetallic model

The equilibrium equations are written in the following forms

$$
\begin{gathered}
d \sigma(T i) g(h-\lambda)+d \sigma(S t) g \lambda-d F=0 \\
d \sigma(T i) g(h-\lambda)(h+\lambda) / 2+d \sigma(S t) g \lambda 2 / 2 \\
-d F h / 2-d M=0
\end{gathered}
$$

where: $d \sigma(\mathrm{Ti}), \mathrm{d} \sigma(\mathrm{St})-$ stress increments in titanium and steel layers, respectively; $\mathrm{dF}$ - force increment, $\mathrm{dM}$ - moment increment. Equation (9) is treated as the aim function that together with the constitutive equations of material hardening is solved incrementally in Matlab software. Residuals $\operatorname{Er}(\mathrm{t})$ of equation (9) are traced and plotted in Figs. in next paragraph.

\section{SIMMULATIONS}

Analysis of influence of sinusoidal loading $F(t)=$ $F_{a} \sin (2 \pi f t)$ (where $f$ - frequency of loading; $f=4 \mathrm{~Hz}$ ) on cyclic behavior bimetallic layers was performed with force amplitude $F_{a}=24500 \mathrm{~N}$ that corresponds to experimental fatigue life $N_{\text {exp }}$ equal to 26570 cycles. The observed ratcheting phenomenon for this specimen is shown in Fig. 4. Fig. 5 presents the changes in mean value of total strain cycle by cycle. The mean strain rate oscillates around $10^{-7} 1 /$ cycle.

In simulations two initial stress state were considered (Tab. 5). In the case 0 it is assumed that residual stresses in both metals are equal to zero and in the second case it is assumed that residual stress state in titanium is $-100 \mathrm{MPa}$ ( $\mathrm{z}$ direction, Fig. 3). The negative value comes from residual stress measurement and analysis of the heat treatment process (Karolczuk et al.
2014). The positive value of residual stress in steel comes from the equilibrium of forces.

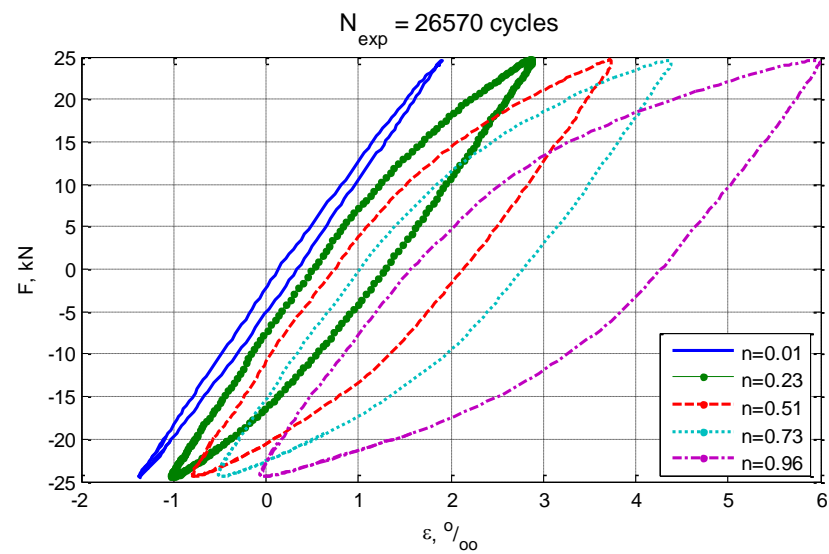

Fig. 4. Hysteresis loops $F-\varepsilon$ showing ratcheting phenomenon, i.e. strain accumulation in direction of tension, where $n=N / N_{\text {exp }}$ (damage degree)
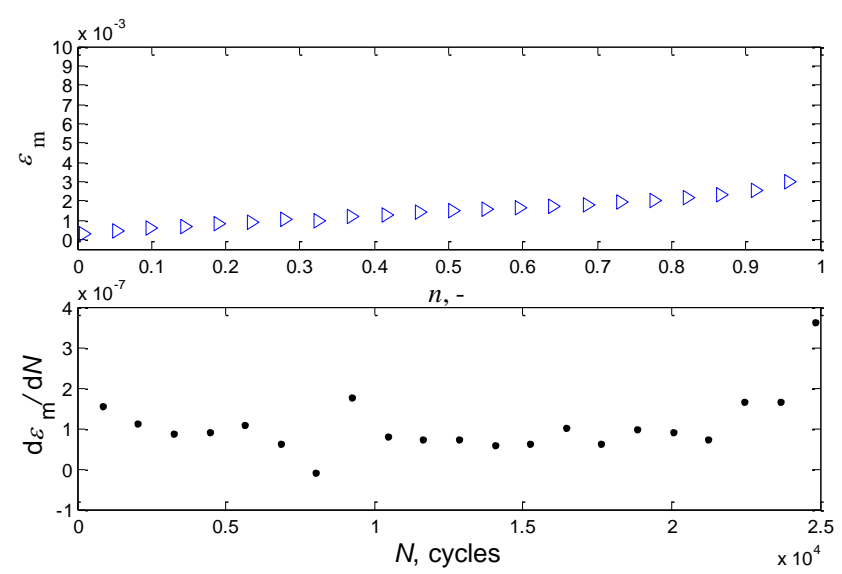

Fig. 5. Evolution of mean value of total strain and estimated mean strain rate

Tab. 5. Simulation cases

\begin{tabular}{|c|c|c|}
\hline Material & Titanium Grade 1 & S355J2+N \\
\hline Simulation & $\sigma_{\text {res, }} \mathrm{MPa}$ & $\sigma_{\text {res }, \mathrm{MPa}}$ \\
\hline 0 & 0 & 0 \\
\hline 1 & -100 & 50 \\
\hline
\end{tabular}

Results of simulations are presented in Figs. 6 and 7, where: (a), (b) final positions or yield surfaces in space $\sigma_{z}-\sigma_{y}$ for steel and titanium, respectively; (c) stress courses for steel and titanium; (d) strain courses; (e) hysteresis loops; (f) residuals of Eq. 9.

It could be noticed that the maximum value of $\operatorname{Er}(t)$ does not exceed the value of 5.10-6 N. The strain amplitudes and mean values are stabilized after tens of cycles. Detailed analysis of stability of strain courses is presented in Figs. 8-11. Figs. 8a and 10 a present simulated hysteresis loops $F-\varepsilon$, where $\varepsilon$ is calculated without the residual stress influence, i.e. the starting point is assumed as $F(t=0)=0$ then $\varepsilon(t=0)=0$ (in titanium and steel layers, as measured by extensometer during fatigue test). Figs. $8 \mathrm{~b}$ and $10 \mathrm{~b}$ present the changes in the amplitudes and mean values of strain during subsequent cycles. 

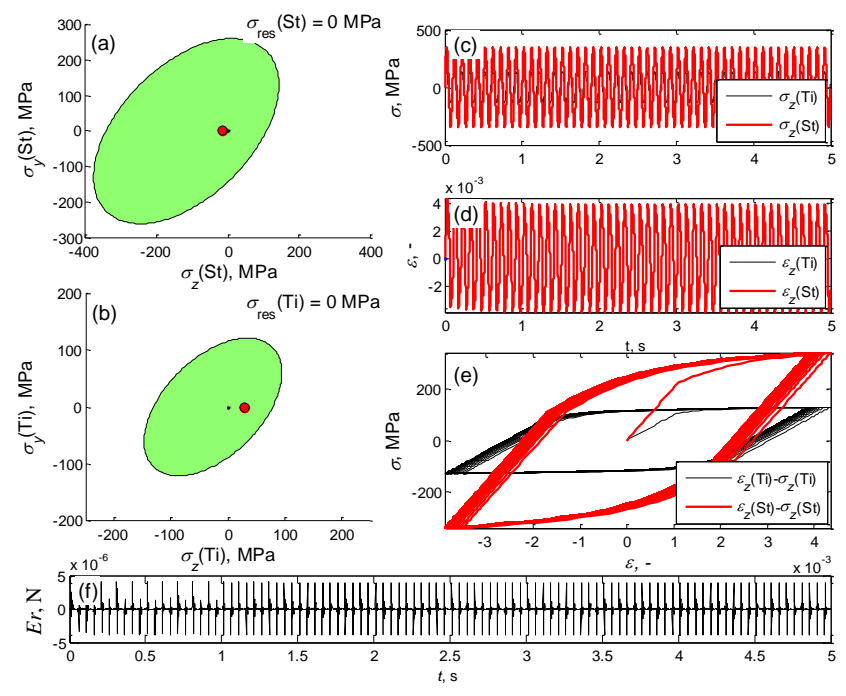

Fig. 6. Behavior of bimetal under cyclic loading and case 0 of simulation
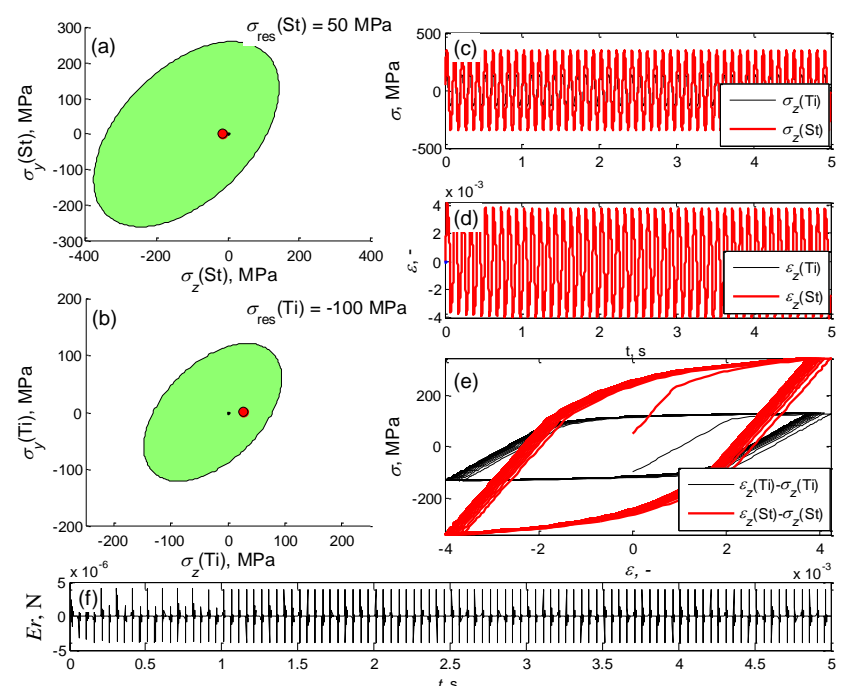

Fig. 7. Behavior of bimetal under cyclic loading and case 1 of simulation
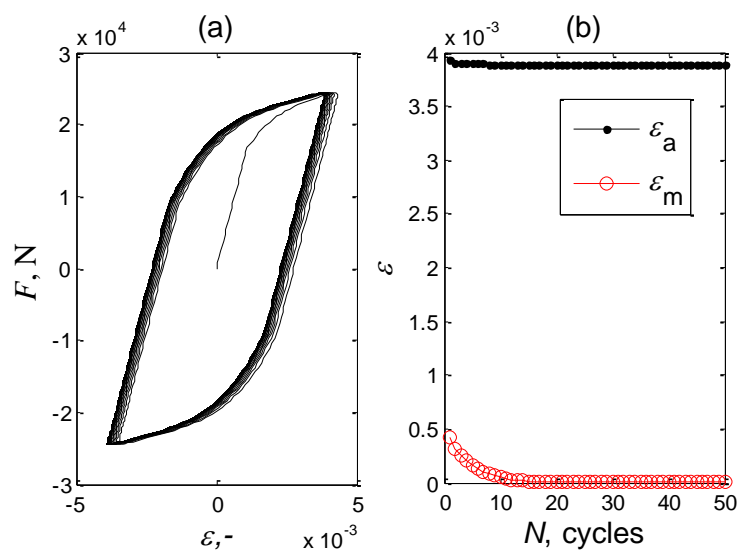

Fig. 8. Simulation: case 0 . (a) Hysteresis loops $\varepsilon-F$;

(b) strain amplitudes $\varepsilon_{a}$ and mean values $\varepsilon_{m}$

in function number of cycles $N$

The rates of strain amplitudes $d \varepsilon_{a} / d N$ and mean values $d \varepsilon_{m} / d N$ show precisely that for case 0 of simulation the strain rates achieve value below 10-10 $1 /$ cycle after 37 cycles and for case 1 of simulation the strain rates achieve value below 10-10
$1 /$ cycle after 49 cycles. The rate value equal to $10^{-10} 1 /$ cycle could be treated as stabilization since, e.g. after $10^{6}$ cycles the accumulated strain would be equal to $10^{-4}$, i.e. around $2.5 \%$ of strain amplitude. In case 1 of simulation the mean value of stress, i.e. residual stresses are relaxed very quickly in a few first cycles.

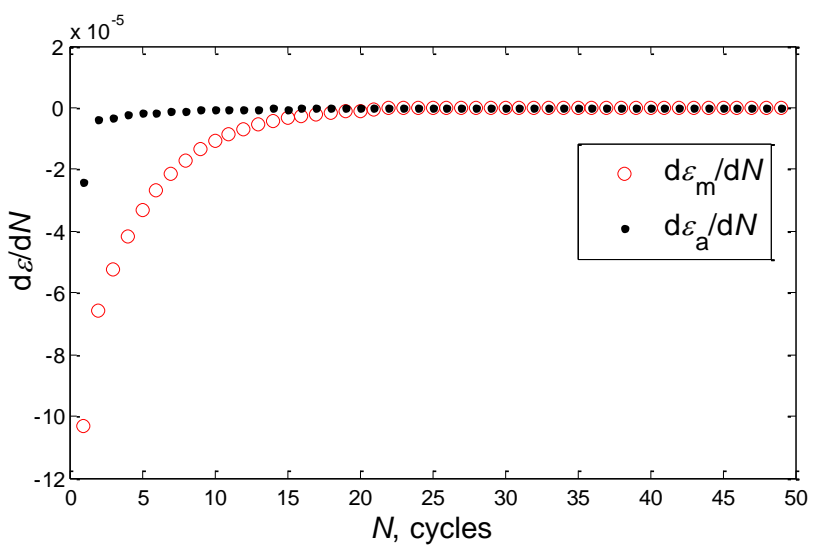

Fig. 9. Simulation: case 0 . Rates of strain amplitudes $\varepsilon_{a}$ and mean values $\varepsilon_{m}$ in function number of cycles $N$

The conclusion is that different cyclic properties of parent materials and even existence of residual stresses are not the cause of the experimentally observed ratcheting phenomenon.
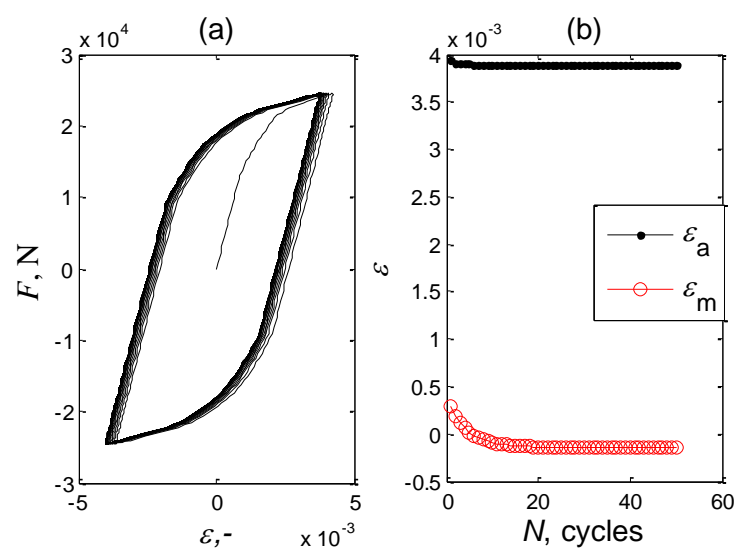

Fig. 10. Simulation: case 1. (a) Hysteresis loops $\varepsilon-F$; (b) strain amplitudes $\varepsilon_{a}$ and mean values $\varepsilon_{m}$ in function number of cycles $\mathrm{N}$

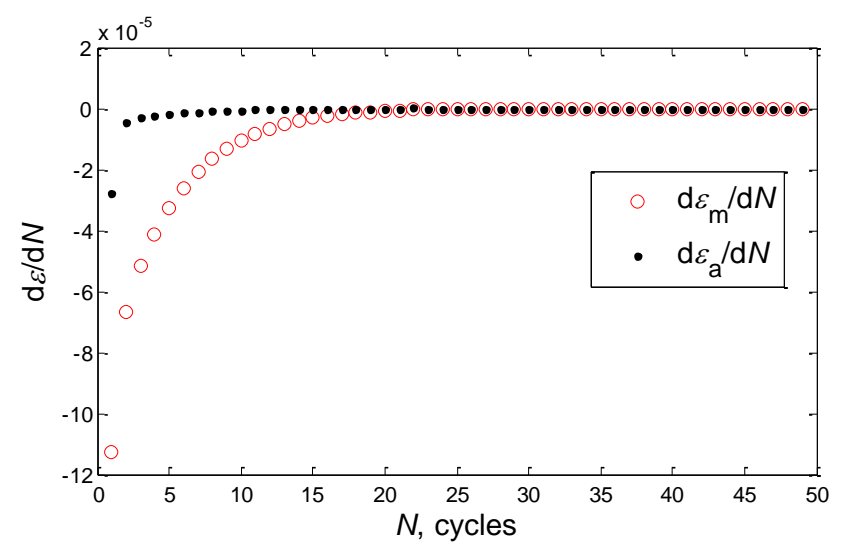

Fig. 11. Simulation: case 1. Rates of strain amplitudes $\varepsilon_{a}$ and mean values $\varepsilon_{m}$ in function number of cycles $\mathrm{N}$ 
The other reasons of ratcheting phenomenon in the analyzed bimetal that could be consider are specific structural and mechanical properties of joint area. During the collision of flayer plate with base plate very high pressure around $19-50 \mathrm{GPa}$ is created in time around 2-5 $\mu$ s (Walczak, 1989; Crossland, 1982) as a result thin very hard layer of intermetallics is formed (Paul et al., 2011) sometimes with larger local melted areas. Those melted areas could already have very short cracks (Fig. 12) before fatigue test. The melted areas could be the places of stress concentration and fatigue crack initiators (Fig. 13).

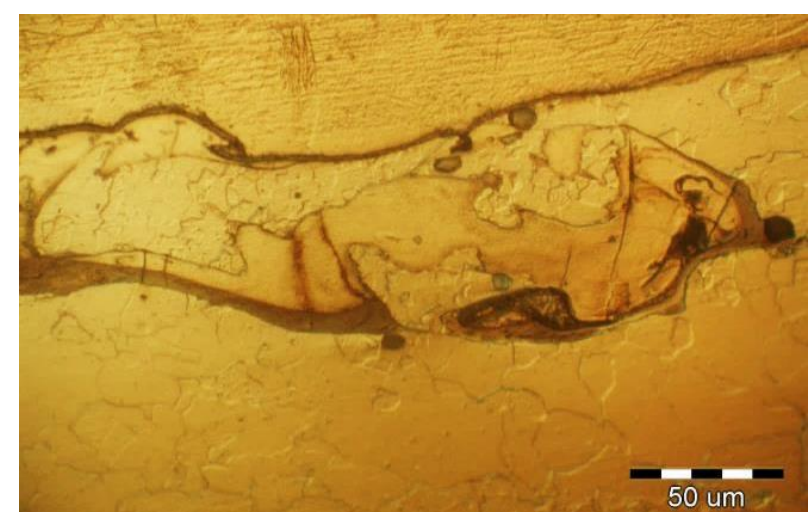

Fig. 12. Photo of joint area of one of tested bimetallic specimen before fatigue test

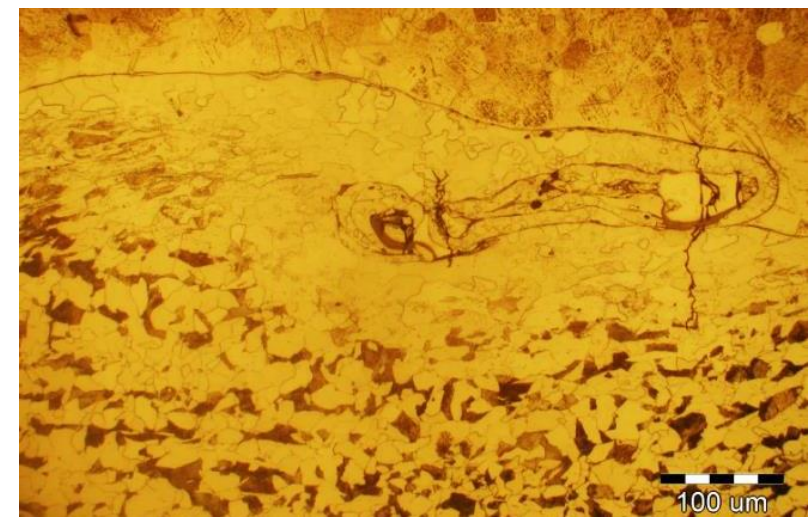

Fig. 13. Photo of joint area after fatigue test (steel - low part of photo)

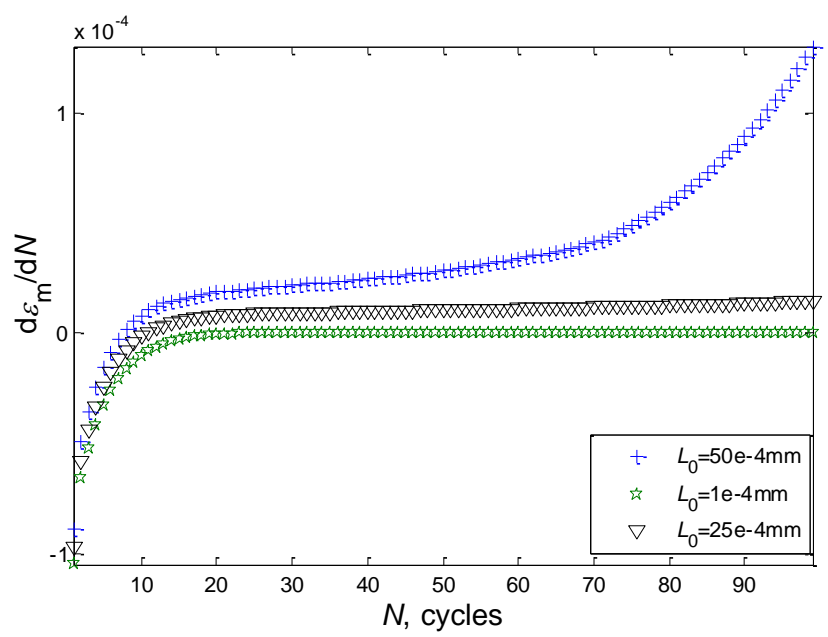

Fig. 14. Simulation with different crack lengths $L_{0}$. Rates of strain mean values $\varepsilon_{m}$ in function number of cycles $N$ for different crack lengths
In the third simulation the micro crack with length $L_{0}$ is introduced into model. This introduction is very simplified just in order to simulate the difference in force transmission between tension and compressive period of loading. Thus, under tension the crack decreased the cross section of specimen by $L_{0}-g$ (Fig. 3 ) equally in both layers and under compressive period the cross section is not changed. The tension period were defined as $\varepsilon(t)>0$ and $d F / d t>0$. The results of simulations are presented in Fig. 14.

Fig. 14 shows that the strain rate of mean values strongly depends on the simulated crack length. For the crack length equal to $0.0001 \mathrm{~mm}$ the strain rate is close to experimental one, i.e. $10^{-7}$ 1/cycle (Fig. 5).

\section{CONCLUSIONS}

- Different elastic-plastic properties of parent materials used in the applied bimetallic and material models cannot explain the ratcheting phenomenon.

- The ratcheting phenomenon could be simulated using asymmetrical geometrical model of bimetal, i.e. cross area reduced under tension period of loading.

- The simulated strain rate using asymmetrical geometrical model of bimetal is very sensitive to the applied asymmetry.

\section{REFERENCES}

1. Chaboche J., Dang Van K., Cordier G. (1979), Modelization of the strain memory effect on the cyclic hardening of 316 stainless steel, Structural mechanics in reactor technology. Transactions, Vol. L, 1-10.

2. Chaboche J.-L., Kanouté P. \& Azzouz F. (2012), Cyclic inelastic constitutive equations and their impact on the fatigue life predictions, International Journal of Plasticity, 35, 44-66.

3. Crossland B. (1982), Explosive welding of metals and its application, Clarendon Press, Oxford.

4. Findik F. (2011), Recent developments in explosive welding, Materials \& Design, 32 (3), 1081-1093.

5. Ganczarski A., Szubartowski D. (2015), On The Stress Free Deformation Of Linear FGM Interface Under Constant Temperature, Acta Mechanica et Automatica, 9(3), 135-139.

6. Gloc M., Wachowski M., Plocinski T., Kurzydlowski K.J. (2016), Microstructural and microanalysis investigations of bond titanium grade1/low alloy steel st52-3N obtained by explosive welding, Journal of Alloys and Compounds, 671, 446-451.

7. Gómez C., Canales M., Calvo S., Rivera R., Valdés J.R., Núñez, J.L. (2011), High and low cycle fatigue life estimation of welding steel under constant amplitude loading: Analysis of different multiaxial damage models and in-phase and out-of-phase loading effects, International Journal of Fatigue, 33 (4), 578-587.

8. Hubel H. (1996), Basic conditions for material and structural ratcheting, Nuclear Engineering and Design, 162(1), 55-65.

9. Karolczuk A., Kowalski M. (2014), Fatigue phenomena in steeltitanium bimetallic composite (in Polish), Politechnika Opolska, Opole, Poland.

10. Karolczuk A., Kowalski M., Bański R., Żok F. (2013), Fatigue phenomena in explosively welded steel-titanium clad components subjected to push-pull loading, International Journal of Fatigue, 48, 101-108.

11. Karolczuk A., Kowalski M., Kluger K., Żok F. (2014), Identification of Residual Stress Phenomena Based on the Hole Drilling Method in Explosively Welded Steel-Titanium Composite, Archives of Metallurgy and Materials, 59 (3), 1129-1133. 
12. Lazurenko D.V., Bataev I.A., Mali V.I., Bataev A.A., Maliutina I.N., Lozhkin V.S., Esikov M.A., Jorge A.M.J. (2016), Explosively welded multilayer Ti-Al composites: Structure and transformation during heat treatment, Materials and Design, 102, 122-130.

13. Paul H., Faryna M., Prażmowski M., Bański R. (2011), Changes in the bonding zone of explosively welded sheets, Archives of Metallurgy and Materials, 56 (2), 463-474.

14. Paul H., Lityńska-Dobrzyńska L., Miszczyk M., Prażmowski M. (2012), Microstructure and Phase Transformations Near the Bonding Zone of Al/Cu Clad Manufactured by Explosive Welding, Archives of Metallurgy and Materials, 57 (4), 1151-1162.

15. Song J., Kostka A., Veehmayer M., Raabe D. (2011), Hierarchical microstructure of explosive joints: Example of titanium to steel cladding, Materials Science and Engineering: A, 528 (6), 2641-2647.
16. Sulym H., Pasternak I., Tomashivskyy M. (2016), Boundary Integral Equations for an Anisotropic Bimaterial with Thermally Imperfect Interface and Internal Inhomogeneities, Acta Mechanica et Automatica, 10 (1), 66-74.

17. Walczak Z. (1989), Explosive welding (in Polish),WNT.

The Project was financed from a Grant by National Science Centre (Decision No. DEC-2011/03/B/ST8/05855). 